\title{
A Study on Strengthening of Concrete Structures
}

\section{Gomasa Ramesh}

Abstract: Concrete is the most commonly used building material due to its high strength, moldability, weather-resistant, and fire resistance, among other benefits. In recent years, there has been a growth in the usage of Micro Silica fume. Through the Ore sand Bridge building, records show that Micro Silica was used in the concrete. These fabrics are not only environmentally sustainable, but they also have technological advantages on both new and hardened mortar products. Both goods are agricultural by-products, but their usage decreases the amount of primary raw materials removed from the earth. Latent hydraulic content is micro silica fume and fly ash. It has intrinsic cementation effects, which must be activated. Combining the powder with Portland cement is a popular way to achieve these results. Pozzolana is the name given to pulverized fly ash. These materials may not have intrinsic cementation properties, but a cementation substance is created when mixed with a high alkaline material.

Keywords: Micro Silica, Concrete, Tests, Strengthening.

\section{INTRODUCTION}

Micro silica Fume is a term that refers to a small amount of silica. Micro Silica is a small material that is mixed into the concrete mixture early on. The lowpermeability concrete results would have better mechanical properties and be more resistant to chlorides, sulphates, fumes, frost assault, and alkali-silica reaction. Micro Silica fume concretes have performed well in these conditions. Reduce concrete permeability: The permeability of concrete is the most important property for providing concrete that is resistant to the most aggressive environment. Reduces adverse reactions such as sulphate attack and reinforcement corrosion by reducing the ingress of water or chemicals. A dense impermeable pore structure is created when Micro Silica fume reacts with calcium hydroxide, released as cement hydrates. Although the Micro Silica fume concrete has a similar total porosity to OPC concrete, the average pore size is much smaller, resulting in a significant reduction in permeability. Enhance concrete's mechanical properties and in addition to saving money.

\section{METHODOLOGY}

\section{Mechanisms in Motion}

Calcium hydroxide is released when Portland cement in the concrete reacts chemically. The Micro Silica fume reacts with the calcium hydroxide to form calcium Micro Silicate hydrate.

Manuscript received on 11 May 2021 | Revised Manuscript received on 13 May 2021 | Manuscript Accepted on 15 November 2021 | Manuscript published on 30 November 2021. * Correspondence Author

Gomasa Ramesh*, Department of Civil and Structural Engineering Vaagdevi College of Engineering, Warangal, 506005, Telangana, India EMail:rameshgomasa1@gmail.com

(C) The Authors. Published by Lattice Science Publication (LSP). This is an open access article under the CC-BY-NC-ND license (http://creativecommons.org/licenses/by-nc-nd/4.0/)

\section{Utilization of Micro Silica Fume}

For many years, micro silica fume has been used in mortars, mostly in ready-to-use retarded mortars. Dry silos are becoming more popular, and Micro Silica fume is also being used in this method of mortar production. Micro Silica fume has typically been used as a $5-12 \%$ substitute for Portland cement, with or without lime.

\section{Uses of Micro Silica Fume}

Micro Silica fume is consumed more than one million tons annually around the world. Micro Silica fume is white. It is usually supplied in the UK as a slurry and is made up of powder and water.

\section{Micro Silica Fume in Technical Connection}

Micro Silica Fume from La Adcrete is mainly used to enhance the properties of hardened concrete where improved hardness and resistance to chlorides, sulphates, abrasion, frost assault, and alkali-silica reaction are needed.

\section{Micro Silica Fume Has Many Benefits}

- Reduces permeability by preventing moisture and aggressive elements from penetrating.

- Significant decrease in chloride ion penetration due to the reduction of continuous capillary pores.

- Mechanical properties have been improved. During construction, Micro Silica Fume has several advantages, including:

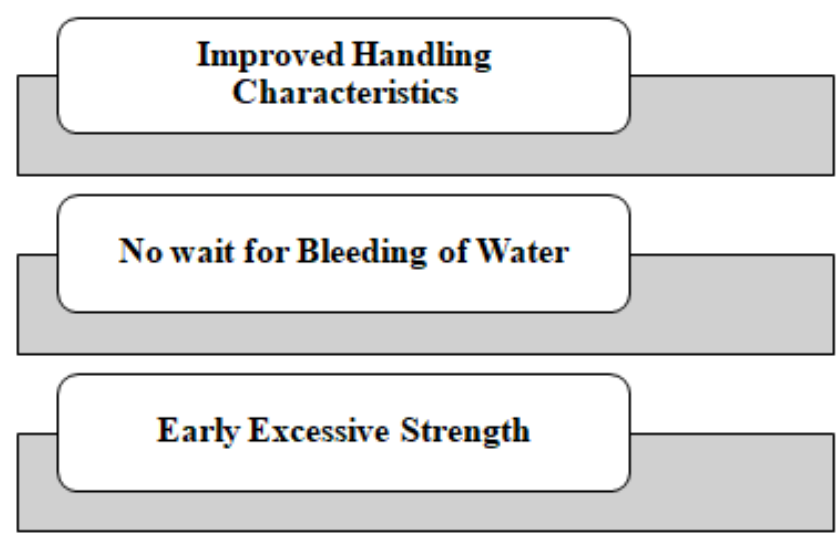

\section{A Micro Silica Fume's Characteristics}

- Micro Silica fume-enhanced concrete has a dense microstructure.

- Permeability is reduced, and durability is increased.

- Higher modulus of elasticity and flexural strength than conventional concretes of equal compressive strength.

- Micro Silica fume can be added to high-performance concretes with microfibers to prevent explosive spalling.

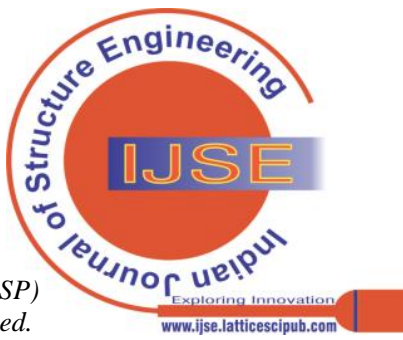


- Wide range water reducing admixture can be used in Micro Silica-fume concrete to obtain optimum strength and longevity.

Improve concrete's sulphate tolerance: Before discussing the benefits of utilizing Micro Silica fume to improve concrete's sulphate resistance, it's worth noting the specific types of sulphate attacks and the properties of sulfateresistant cement. Sulfate-resistant cement has been developed in response to the usage and degradation of concrete in sulfate-rich conditions. Necessary studies into the usage of supplementary cementations products to enhance sulphate tolerance have also resulted from it. Tolerance to sulphate attack has been extensively researched. To - the chance of sulphate attack, sulphate resistant cement has a low $\mathrm{C}_{3} \mathrm{~A}$ material. Improve the reinforcement's defense Corrosion. The efficiency of the concrete in terms of sulphate tolerance must be considered for concrete construction in a navigational structure, sulphate strike, according to studies conducted in several countries. Water demand: Micro Silica fumes are known to raise water demand, which is usually mitigated with the usage of admixtures.

\section{Setting Time}

Unlike other SCMs, including slag and fly ash, Micro Silica fume has little effect on setting time. Bleeding: Once the concrete has been laid, the solids have a propensity to settle. Influence the propensity of concrete to bleed. Excessive bleeding may cause a coating of thin laitance. As seen in the Concrete Society Good Concrete Guide. The bleeding in concrete containing Micro Silica fume is significantly decreased. Bleeding would be minimized as the Micro Silica fume dosage is raised.

\section{The Heat of Hydration}

The heat of hydration that is quite close to CEM. Earlyage thermal cracking may be reduced by lowering the earlyage temperature increase, and thorough advice is given in CIRIA Report.

A slower release of heat, on the other hand, will minimize the initial rate of strength increase. When casting small, uncovered parts in winter weather in colder climates.

CEM, I concrete, particularly at lower temperatures, and may also necessitate longer formwork strike times. Before deleting formwork, consider the following considerations: Surface concrete should not be allowed to freeze.

- The concrete must be strong enough to sustain itself by using soffit formwork. The Construct 'Guide to flat slab falsework and formwork' contains general information on striking slab soffits and back propping (CONSTRUCT).

- According to experience, Micro Silica fume alone does not seem to have a noticeable impact on the period it takes to strike formwork. Power in tensile: Concrete's tensile (flexural) strength rises in tandem with its compressive strength.

- As compared to CEM I concrete, Micro Silica fume concrete has a significantly lower tensile strength ratio. According to Hooton, tensile splitting forces as a ratio of compressive power are $10 \%$. At ages of 28 to 182 days.

\section{Concrete Durability}

- Impact Carbonation (protection) of embedded steel: The alkalinity of the cement paste protects steel despite some decrease of calcium hydroxide. The $\mathrm{pH}$ of the cement paste remains strong enough to preserve steel. Carbonation can minimize alkalinity and provide steel safety.

- Its usage would improve the resilience of reinforced concrete systems subjected to chlorides. The reader should consult Concrete Society TR61 "Enhancing Reinforced Concrete Longevity." Sulfate resistance: sulphates attack concrete by chemical and physical processes.

- The first response is more essential in terms of practicality. Both reactions that cause expansion and disruption of the reinforced concrete result in significant volume changes.

- The cement paste is reduced to a soft mulch as a result of its formation. Unfortunately, as opposed to CEM I concrete. The cement matrix dissolves, resulting in the loss of concrete integrity-some lowhardness moorland waters. The strength of the concrete has been known to be more important than the form of cementation content in such harsh conditions.

The alkali-Micro Silica reaction produces a gel that absorbs pore fluid and expands; in some instances, this growth causes significant internal tension in the concrete, resulting in substantial macro-cracking. Sections of the concrete construction that are exposed to moisture suffer destruction. Micro Silica fume may help to reduce the chance of ASR injury. Abrasion resistance: Several influences influence abrasion tolerance of floor slabs. India is one of the world's fastest developed nations. Various fields such as manufacturing, infrastructure, building, agriculture, and so on all play a significant role in achieving overall growth. As a result of this growth, the industrial sector has been compelled to manufacture various required products. These plants and manufacturers have been a source of waste items in addition to manufacturing other usable objects.

This prompted an inquiry into scientific areas that might make greater use of these waste materials. This topic has been the subject of research not only in India but also around the world. Such studies revealed no safer position than the building industry to use a vast quantity of such products more efficiently and cost-effectively. On the other hand, construction has a role in the country's growth, not just by increasing construction work but also by doing it in a more nuanced manner. This, in particular, has an effect on the different components to be used and their amounts. As a result, modern materials were investigated to see whether they could be used for the same reason at a lower cost. The study has been performed in particular on the use of byproducts from different industries. In this way, the building and manufacturing sectors have been connected, reducing environmental risks while still addressing economic concerns.

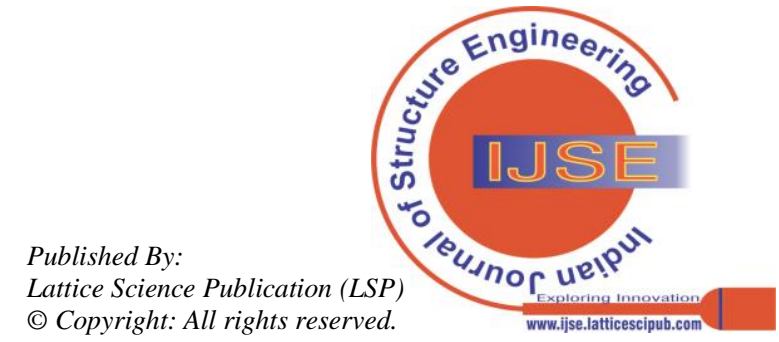


Micro Silica fume, fly powder, blast furnace slag, and other waste materials come from various industries. Both of these have been discovered to be very useful in the building sector. These materials are often used in their original shape or subtly modified to suit a specific function. Based on the above, an attempt was made in this study to use La Adcrete Micro Silica fume as a substitute for cement in the range of $0 \%$ to $20 \%$ by weight, with a mix proportion of 1:1.384:2.988 of 0.48 water-cement ratio.

\section{Investigation Based on Experience}

- The experiment aimed to see how the partial substitution of cement with La Adcrete Micro Silica fume affected the strength of concrete. The testing program was designed to cast and analyze the cubes and research the strength property to accomplish the investigation's objectives. The experimental programs for cubes are described in depth.

- The experimental program is intended to test the workability and compressive power of the MIX under consideration. This blend is intended for concrete of the M20 standard. In this analysis, the critical variable parameter was the dose of MICROMICRO SILICA FUME. Six concrete mixes were cast for MICRO SILICA FUME doses, ranging from $0 \%$ to $20 \%$. According to IS:10086-1982, a total of 18 cubes $(150 \mathrm{X} 150 \mathrm{X} 150) \mathrm{mm}$ were cast.

- Micro Silica is a fine powder applied to the concrete mix early in the mixing phase by La Ad Crete. The low permeability concrete results would have better mechanical properties and be more resistant to chlorides, sulphates, fumes, frost assault, and alkalisilica reaction. Initially, all the components were weigh batched. Cement, La Adcrete Micro Silica fume were blended to which coarse aggregate and fine aggregate were applied and thoroughly mixed. Water was weighed precisely and applied to the dry mix until it was carefully blended to get a consistent concrete, demarcated by obtaining a uniform colour all over the concrete.

\section{Casting}

The cubes were cast in the moulds of dimension $150 \mathrm{x}$ $150 \times 150 \mathrm{~mm}$ (internal). The traditional cube moulds are put on the table, and well-mixed concrete is poured into the moulds in 3 layers. Each layer is thoroughly compacted, utilizing a standard tamping lane.

\section{Curing}

In a warm water tub, the specimens are left to heal. The specimen was taken out of the oven and left to dry before the curing phase was finished.

\section{Testing}

Once the cubes had been cast and healed, the strength properties were determined. It's a bright idea to use a compression tester. The cubes are placed in a weighing rig for the compressive examination. The loads are added at a steady pace, with readings and loads being registered before the cube breaks down.

\section{Air Content Percent}

The air content entrapped for the nominal aggregate size of $25 \mathrm{~mm}$ is 2 percent from table 3 of IS 10262 . Selection of Sand and water content: For $25 \mathrm{~mm}$ nominal size of aggregate.

\section{RESULTS AND DISCUSSION}

Various changes are observed in the properties of concrete, such as workability, strength, etc., with the variation in percentage replacement with Micro Silica Fume. Here are the observations:

- $\quad$ Fresh concrete: As the percentage of cement replaced with Micro Silica Fume is raised, the slump value rises. As the percentage of cement replaced with micro-silica fume rises, the compaction factor rises with it.

- Hardened concrete: For concrete cubes, the concrete 8 percent replacement of cement with micro-silica fume has performed better, and maximum compressive strength is achieved.

- Concrete with 8 percent replacement has performed better at all 28-days of the curing period.

\section{CONCLUSION}

- The following are the conclusions derived by replacing the cement content with Micro Silica Fume in different proportions varying up to 20 percent. The compressive strength of the concrete mix improved with the replacement of micro-Silica Fume at 8 percent replacement and 28 days of curing.

- The concrete with 0 percent replacement is affected severely against sulphate ion attack resulting in mass deterioration. In comparison, triple blended with 8 percent replacement were affected only very slightly at all stages of immersion.

- The workability of concrete mix has been improved with increasing percentage replacement of cement with supplementary cementitious materials. It was concluded that there are no technological, fiscal, or environmental obstacles that occur while utilizing most triple blended cement concrete mixtures.

- The technological efficiency of the triple blended concrete mixtures that were tested was often higher than Ordinary Portland Cement concrete mixtures. The triple blended cement displayed improved compressive strength against sulphate ion assault.

\section{REFERENCES}

1. Gomasa Ramesh, Dharna Ramya, Mandala Sheshu Kumar; "Health Monitoring of Structures by Using Non-Destructive Testing Methods", International Journal of Advances in Engineering and Management (IJAEM) Volume 2, Issue 2, pp: 652-654, DOI: 10.35629/5252-45122323.

2. Gomasa Ramesh, Doddipati Srinath, Mandala Sheshu Kumar; "Earthquake Resistant of RCC Structures" Published in International Journal of Trend in Scientific Research and Development (ijtsrd), ISSN: 2456-6470, Volume-4, Issue-5, August 2020, pp.808-811.

3. Gomasa Ramesh, Doddipati Srinath, Mandala Sheshu Kumar, "Importance of Dynamic Analysis for RCC Structures", International Journal for Modern Trends in Science and Technology, 6(8): 271276, 2020, DOI: 10.46501/IJMTST060844. [CrossRef]

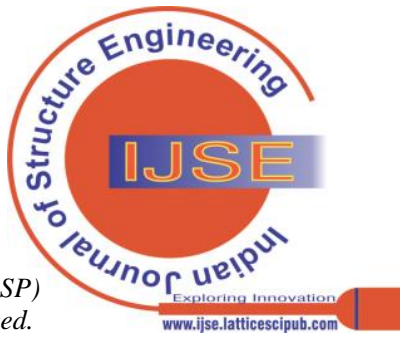




\section{A Study on Strengthening of Concrete Structures}

4. Gomasa Ramesh, Mandala Sheshu Kumar and Palakurthi Manoj Kumar, "Introduction to Finite Element Methods in Engineering", International Journal for Modern Trends in Science and Technology, 6(9): 167-174, 2020, DOI: 10.46501/IJMTST060926. [CrossRef]

5. Gomasa Ramesh, "Study on Mechanical Properties of Polyurethane Foam Concrete", Indian Journal of Structure Engineering (IJSE) Volume-1 Issue-1, May 2021, pp:1-3, DOI:10.35940/ijse.B8005.051121. [CrossRef]

6. Gomasa Ramesh, "Importance and Applications of GIS in Engineering", Indian Journal of Structure Engineering (IJSE) Volume-1 Issue-1, May 2021, pp:4-8, DOI:10.35940/ijse.B8005.051121. [CrossRef]

7. Gomasa Ramesh, "Transparent Concrete: A Review", Indian Journal of Structure Engineering (IJSE) Volume-1 Issue-1, May 2021, pp:48, DOI:10.35940/ijse.B8005.051121. [CrossRef]

8. Gomasa Ramesh, "Pervious Concrete: A Review", Indian Journal of Structure Engineering (IJSE) Volume-1 Issue-1, May 2021, pp:4-8, DOI:10.35940/ijse.B8005.051121. [CrossRef]

9. Gomasa Ramesh, Maddela Jyothi Kiran, Palakurthi Manoj Kumar, "A Study on Geopolymer Concrete", International Journal of Innovative Research in Science, Engineering and Technology (IJIRSET), Volume10, Issue 4, April 2021, pp:3818-3824, DOI:10.15680/IJIRSET.2021.1004142.

10. Gomasa Ramesh, "Low Carbon Buildings for Sustainable Constructions", Indian Journal of Structure Engineering (IJSE) Volume-1 Issue-2, November 2021, PP:1-4, DOI:10.35940/ijse.B8003.111221. [CrossRef]

11. Gomasa Ramesh, "Geopolymer Concrete: A Review", Indian Journal of Structure Engineering (IJSE) Volume-1 Issue-2, November 2021, PP:5-8, DOI:10.35940/ijse.A1302.111221. [CrossRef]

12. Gomasa Ramesh, "Self-Compacting Concrete: A Review", Indian Journal of Structure Engineering (IJSE) Volume-1 Issue-2, November 2021, PP:9-12, DOI:10.35940/ijse.A1303.111221. [CrossRef]

13. Gomasa Ramesh, "Slope and Landslide Stabilization: A Review", Indian Journal of Structure Engineering (IJSE) Volume-1 Issue-2, November 2021, PP:13-16, DOI:10.35940/ijse.A1304.111221. [CrossRef]

14. Gomasa Ramesh, D Srinath, "Repair, rehabilitation and retrofitting of reinforced concrete structures by using non-destructive testing methods," March 2021, Materials Today: Proceedings, DOI: 10.1016/j.matpr.2021.02.778 [CrossRef]

15. D Srinath, G Ramesh, "Mechanical properties of sustainable concrete by using RHA and hydrated lime," March 2021, Materials Today: Proceedings, DOI: 10.1016/j.matpr.2021.02.785 [CrossRef]

16. Gopu Anil, Gomasa Ramesh and Dr. Annamalai Rangasamy Prakash, "An Experimental Study Investigation on Self Compacting Concrete and Strength Properties by using Fiber Reinforcement", International Journal for Modern Trends in Science and Technology, Vol. 07, Issue 02, February 2021, pp.-93-96, DOI: 10.46501/IJMTST0702016.

17. Dharna Ramya, Gomasa Ramesh and Dr. Annamalai Rangasamy Prakash, "Shear Behavior of Hybrid Fiber Reinforced Concrete", International Journal for Modern Trends in Science and Technology, Vol. 07, Issue 02, February 2021, pp.-79-82, DOI: 10.46501/IJMTST0702013.

18. Bandi Pooja, Gomasa Ramesh and Dr. G. Dinesh Kumar, "Experimental Study on Mechanical Properties of Geopolymer Concrete by using Fly Ash and RHA", International Journal for Modern Trends in Science and Technology, Vol. 07, Issue 02, February 2021, pp.-50-55, DOI:10.46501/IJMTST0702008.

19. Sriramoju Sravani, Gomasa Ramesh and Dr. G. Dinesh Kumar, "Study on Percentage Replacement of Cement by Glass powder for M20 Grade Concrete", International Journal for Modern Trends in Science and Technology, Vol. 07, Issue 02, February 2021, pp: 129132, DOI:10.46501/IJMTST0702022.

20. Bonagani Vamshi Krishna, Gomasa Ramesh and Dr. Annamalai Rangasamy Prakash, "Effect of Geo-Activator on Strength and Durability Properties of Geopolymer Concrete", International Journal for Modern Trends in Science and Technology, Vol. 07, Issue 03, March 2021, pp.: 123-126, DOI: 10.46501/IJMTST0703022.

\section{AUTHORS PROFILE}

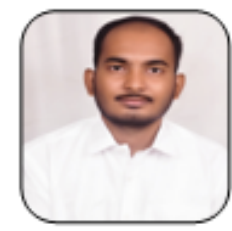

Mr. Gomasa Ramesh, B. Tech Civil Engineering, M. Tech Structural Engineering, Vaagdevi College of Engineering, Warangal, 506005, Telangana, India. Presented and participated in various International conferences and National Conferences and received Best Paper Awards for some Papers and received Best Young Researcher Award for 2020. Published more than 20 Research Papers in International Peer-Reviewed UGC Journals. Member of various Professional Bodies American Society of Civil Engineers, Structural Engineering Institute, Institute of Structural Engineering, American Concrete Institute and American Society of Testing Materials etc.

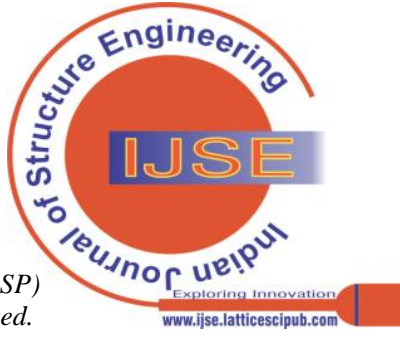

